\title{
Características da Formação de Professores de Ciências Naturais
}

\section{Characteristics of the Education of Natural Sciences Teachers}

\author{
Maria Estela Gozzi ${ }^{\circledR}$ Brasil \\ Maria Aparecida Rodrigues ${ }^{\circledR}$ Brasil
}

Este texto discute a formação de professores para a disciplina de Ciências Naturais nos anos finais do ensino fundamental. Priorizamos investigar a discussão da categoria interdisciplinaridade socializada como fundamental para a integração curricular que fundamenta essa disciplina. Nossa proposta é analisar se tal categoria tem subsidiado a formação de docentes. De nossa perspectiva, a ausência de Diretrizes Curriculares Nacionais e as dificuldades que permeiam a oferta desse curso podem indicar uma desvalorização dessa Licenciatura ao passo que, nesse mesmo contexto, encontramos as Diretrizes Curriculares para cursos específicos como Física, Química e Biologia. Elas compõem a área de Ciências e habilitam os docentes para a atuação na disciplina de Ciências do ensino fundamental. Consideramos a necessidade de uma formação docente que atenda às características de um perfil de profissional adequado aos propósitos de ensino dessa disciplina no ensino fundamental. Pautamo-nos na legislação do ensino de Ciências Naturais e da formação de professores para a educação básica. Estudamos propostas de Licenciatura em Ciências Naturais e de Ciências Biológicas de três universidades: a Universidade Estadual de Maringá (UEM); a Universidade Federal do Estado do Rio de Janeiro (UNIRIO) e a Universidade de São Paulo (USP). Além disso, utilizamos fontes orais, nomeadamente entrevistas a professores experientes na atuação das disciplinas que compõem essa área. A discussão dos dados levantados é orientada pela análise dos propósitos teóricos apontados pelo "ciclo de políticas" e também pela abordagem que valoriza as diferentes variáveis envolvidas no processo educacional.

Palavras-chave: Ciências Naturais; Formação de professores; Perfil docente.

This text discusses the education of natural sciences teachers who teach the last years of elementary school. The investigation of the discussion of the category socialized interdisciplinarity was prioritized as a fundamental part of the curricular integration on which this discipline is based. The proposal is to analyze if this category has supported teacher education. From the perspective of this study, the absence of national curricular guidelines and the difficulties that permeate the offering of this course may indicate a devaluation of this teaching course; whereas, in this same context, there are curricular guidelines for specific courses such as physics, chemistry and biology. They compose the area of sciences and enable teachers to teach sciences in elementary school. This 
paper considers the necessity of a teacher education that attends the characteristics of a professional profile that is adequate to the teaching proposals of this discipline in elementary school and is based on legislation concerned with natural sciences teaching and teacher education for basic education. Proposals of natural sciences teaching courses and biological sciences were studied at three universities: Universidade Estadual de Maringá (UEM); Universidade Federal do Estado do Rio de Janeiro (UNIRIO); Universidade de São Paulo (USP). In addition, oral sources were used, namely interviews of teachers experienced in the disciplines that compose this area. Discussion of the surveyed data is guided by the analysis of the theoretical proposals indicated by a "policy cycle" and also by an approach that values the different variables involved in the educational process.

Keywords: Natural sciences; Teacher education; Teacher profile.

\section{Introdução}

O objeto desta investigação, que gira em torno da formação de professores de Ciências Naturais, é o fato de que, na atualidade, a licenciatura relacionada a essa área carece de Diretrizes Curriculares Nacionais. A escolha foi motivada pelo Processo $n^{\circ}$ 1157/10 de Renovação do Reconhecimento do Curso de Graduação em Ciências - Licenciatura da Universidade Estadual de Maringá (UEM) - Campus Regional de Goioerê. Nesse processo, foi sugerida a alteração da nomenclatura: em lugar de Curso de Ciências deveria se adotar Ciências Biológicas. Consta no Parecer CEE/CES nº190/10 a justificativa para essa sugestão de mudança. Com essas observações, o parecerista recomendou à UEM:

[...] que proceda a alteração de seu Projeto Pedagógico do Curso de Graduação em Ciências - Licenciatura, para Curso de Graduação em Ciências Biológicas - Licenciatura, visto a inexistência de Diretrizes Curriculares Nacionais para o Curso, bem como o baixo número de alunos matriculados, conforme relato do Perito (fls. 225).

Essa solução, que parece tão fácil, causou desconforto e inquietação entre os docentes e discentes do Curso. Assim, em razão de nosso envolvimento com a docência nessa Licenciatura em Ciências Naturais, decidimos conhecer, por meio de um resgate histórico, os diferentes fatores que contribuem para o direcionamento do ensino nessa disciplina nos dias atuais.

As dificuldades que permeiam a oferta desse Curso e a ausência de Diretrizes Curriculares Nacionais podem ser indicativas da desvalorização dessa Licenciatura. A legislação atual contempla as Diretrizes Curriculares para cursos específicos, como Física, Química e Biologia. Consideramos, assim, importante questionar os motivos da inexistência de Diretrizes para os Cursos de Ciências Naturais, voltados para a formação de professores para os anos finais do ensino fundamental, cujo foco tem sido a formação de um professor generalista.

Orientamo-nos por uma série de indagações: 
- Qual a formação docente adequada para ensinar Ciências Naturais nos anos finais do ensino fundamental?

- Os currículos da Licenciatura em Ciências Naturais pautam-se em encaminhamentos teórico-metodológicos específicos para essa disciplina?

- Os currículos das Ciências Biológicas oferecem uma formação que atenda ao encaminhamento teórico-metodológico da integração curricular, conforme proposto para essa disciplina?

Com esses questionamentos, definimos os objetivos da pesquisa: investigar o encaminhamento teórico-metodológico dado a essas duas licenciaturas e, assim, verificar em que medida suas Propostas Curriculares atendem aos propósitos de formação do docente para atuar nas disciplinas de Ciências Naturais nos anos finais do ensino fundamental.

Nossas referências em termos de legislação são os Parâmetros Curriculares Nacionais: terceiro e quarto ciclos que norteiam o ensino de Ciências Naturais, as Diretrizes Curriculares Nacionais para a Educação Básica, bem como as Diretrizes Curriculares Nacionais para a formação dos profissionais do magistério da educação básica. Esses serão os parâmetros para a análise das Propostas Curriculares de formação de professores de Ciências Naturais e de Ciências Biológicas. Quanto aos cursos de licenciatura dessas áreas, selecionamos universidades que representam três estados brasileiros, a saber: o Paraná, com a Universidade Estadual de Maringá (UEM); Rio de Janeiro, com a Universidade Federal do Estado do Rio de Janeiro (UNIRIO) e São Paulo, com a Universidade de São Paulo (USP) ${ }^{1}$.

A seleção dos projetos pedagógicos foi, primeiramente, direcionada a analisar as licenciaturas oferecidas pela UEM - Paraná, Instituição em que atuamos como professoras em seu Curso de Licenciatura em Ciências. Posteriormente, acrescentamos projetos de outras instituições: o da USP, porque esta Instituição sediou o Fórum Brasileiro de Coordenadores e Professores, ocorrido em 2011, cujo tema central foi a formação docente necessária às Ciências Naturais; o da UNIRIO, pela disponibilidade dos projetos pedagógicos no site da Instituição e também porque o estado do Rio de Janeiro vem apresentando diversas contribuições e desenvolvendo grandes pesquisas a respeito do tema de nosso interesse. Estas Universidades oferecem os dois cursos em estudo, portanto, foi analisado um total de seis Cursos (Gozzi, 2016).

Como fontes orais, entrevistamos professores experientes no ensino das disciplinas que compõem essa área, a saber: Biologia, Química e Física². A escolha dos professores representantes das diferentes áreas de conhecimento se justifica por

1 Os Projetos foram acessados via internet nos sites das três Instituições Superiores, exceto o do Curso de Licenciatura em Ciências da Natureza da USP, o qual foi enviado à primeira autora, por e-mail em 19/07/2013, pelo então Professor Coordenador do Curso.

2 No decorrer do texto, as referências aos três professores serão feitas da seguinte forma: Biologia - PB, Química - PQ e Física - PF. 
possuírem larga experiência com formação de docentes, contribuir com produção teórica e com organização de textos curriculares para essa área de ensino. Além disso, eles têm vasto conhecimento em suas disciplinas de atuação, orientam grupos disciplinares em propostas para o ensino e para a formação de professores e participam do movimento de renovação do ensino de Ciências em nosso país ${ }^{3}$.

A opção por professores dessas três disciplinas como sujeitos das entrevistas se justifica porque elas compõem a área de Ciências e também porque suas diretrizes curriculares contemplam o preparo de professores que podem atuar nas Ciências Naturais dos anos finais do ensino fundamental, porém com determinações diferenciadas. Além dessas contribuições orais, valemo-nos de textos educacionais produzidos por pesquisadores diversos que vêm se empenhando em contribuir para o entendimento dos vários encaminhamentos educacionais em curso.

Procuramos articular a abordagem teórico-metodológica a respeito da produção de políticas desenvolvida pelos sociólogos Stephen J. Ball e Richard Bowe (Ball, 2001a; 2001b) com a pesquisa de cunho qualitativo. As pesquisas de Ball oferecem recursos intelectuais para entender como os discursos que subsidiam as políticas são produzidos, o que pretendem e como seus efeitos aparecem. Um dos principais conceitos temáticos formulado por Ball para analisar as políticas educacionais é o "ciclo de políticas". Ball (2001a) retoma de Popkewitz (1992) as percepções da política, representando-a como uma rede de interesses éticos, ocupacionais, econômicos e regionais variados. Para Popkewitz, existem grupos de interesse que competem pelo apoio de políticas e recebem apoio do governo. Para Ball (2001a), as políticas educacionais são a expressão de um processo ao mesmo tempo social e pessoal, já que envolve diferentes grupos e pessoas. Esse ciclo foi sistematizado com base em três contextos diferenciados: o da influência; o da produção de texto e o da prática. No contexto de influência, estão o início das políticas públicas e a construção de discursos políticos permeados por interesses mais estreitos e ideológicos e por disputas entre grupos de interesse a respeito das finalidades sociais da educação. No contexto da produção de texto estão os textos políticos e os textos legais oficiais, assim como comentários ou pronunciamentos oficiais resultados de disputas e acordos de grupos. Em face das limitações e das possibilidades de respostas ao conteúdo, situa-se o contexto da prática, cujos efeitos e consequências podem representar alterações nas políticas originais, uma vez que o processo de interpretação pode contribuir para recriar as políticas.

Em nossa análise, buscamos articular essas questões, primeiramente identificando como contexto de influência o histórico da definição da área de Ciências e da necessidade de formação de professores que suprissem essa necessidade de educação. Em seguida, focalizamos o contexto de produção de textos, representado pelos mecanismos institucionais que impulsionam o movimento em prol de cursos de licenciatura e, em particular, a formação de professores de Ciências Naturais. Como contexto da prática

3 A exemplo, dentre as contribuições dos professores entrevistados, estão: produção teórica dos PCN Ciências Naturais, participação em Propostas de Diretrizes Curriculares Estaduais (São Paulo e Rio Grande do Sul), assim como envolvimento com programas de formação de professores para a educação básica. 
que vem se consolidando, estudamos as propostas de licenciaturas selecionadas, a legislação em curso e as falas dos professores entrevistados ${ }^{4}$. Procuramos analisar os dados e discutir os pressupostos teórico-metodológicos que dão amparo à formação do professor, especialmente quanto ao perfil do docente que irá atuar na disciplina de Ciências Naturais com base no referencial teórico orientador da pesquisa.

Reafirmando, o procedimento teórico metodológico desta pesquisa foi relacionar as razões históricas das políticas públicas e educacionais à compreensão de que a produção de textos, dos currículos e das propostas de formação para professores em diferentes áreas de ensino estão sujeitas às interferências globais. A proposta da pesquisa foi a de retomar, no passado, as condições de organização do conhecimento escolar estruturado em disciplinas e, considerando as diferentes tentativas de integração curricular, situar o ensino de Ciências Naturais para os anos finais do ensino fundamental para, a partir daí, apontar iniciativas de formação de professores para ministrar essa área de conhecimento.

Para abordar a questão da formação de docentes para o ensino de Ciências Naturais ${ }^{5}$ nos anos finais do ensino fundamental, precisamos retomar o histórico curricular dessa disciplina. Pautados nesse referencial, podemos discutir qual é a formação necessária para que o professor se torne um profissional capaz de propiciar à criança e ao adolescente condições para que eles estabeleçam relações entre conhecimento científico e contexto social. Selecionamos as categorias interdisciplinaridade e a integração curricular ${ }^{6}$, que dão respaldo à orientação teórico-metodológica da disciplina Ciências Naturais. Procuramos analisar em que medida essas categorias têm subsidiado as propostas de formação de docentes assim como o perfil desejado ao professor.

\section{Contexto de influência: a demanda por ensino de Ciências}

O contexto de influência sinaliza que, no processo histórico em que o currículo da área de Ciências foi se definindo, foram sendo gestados também os discursos sobre a formação de seus professores, discursos esses que não destoaram do movimento geral da reforma educacional. A escola, como primeira instituição a estabelecer a direção, a finalidade e a vontade da sociedade, "associa a organização política, a cultura, a economia

4 As questões orientadoras das entrevistas, reproduzidas a seguir, foram sistematizadas com prioridade para os principais problemas teórico-metodológicos da formação defendida como necessária para os professores de Ciências Naturais, assim como dos temas relacionados ao contexto da prática docente nessa área. "1. O que é mais importante a ser ensinado em Ciências nos dias atuais? 2. As Ciências Naturais compreendem ramos da Astronomia, Biologia, Física, Química e Geociência, o professor formado em Biologia daria conta desse conjunto de conhecimentos? 3. Qual o perfil adequado de um profissional para ensinar Ciências nos anos finais do ensino fundamental? 4. Os currículos de formação de professores de Ciências têm priorizado quais tendências de ensino? 5. O fato de não ter, ainda, Diretrizes Curriculares para as Ciências dos anos finais do ensino fundamental seria um descaso da área abrangente de atuação? 6. De que forma se pode promover a interdisciplinaridade no ensino de Ciências? 7. Quais competências são necessárias para o professor de Ciências favorecer o desenvolvimento de uma postura reflexiva e investigativa do aluno? 8. A especificidade do saber e a especialização do conhecimento constituem uma tendência sem volta?".

5 Usaremos a denominação "Ciências Naturais", conforme consta nos Parâmetros Curriculares Nacionais: terceiro e quarto ciclos do ensino fundamental.

6 Referimo-nos ao discurso de “integração curricular” dos conteúdos de Química, Física, Biologia e Geologia, conforme concepção teórico-metodológica socializada como intrínseca à disciplina de Ciências Naturais. 
e o estado moderno aos padrões cognitivos e motivadores do indivíduo" (Popkewitz, 1997, p.21). No Brasil, à medida que a necessidade de educação se consolidava, o discurso educacional foi sendo impulsionado por aqueles que defendiam a educação para todos. No século XX, essa defesa foi primeiramente socializada pelo Manifesto dos Pioneiros da Educação Nova, passando, posteriormente, a fazer parte da legislação. Na segunda metade desse século, em face da visível deficiência na formação de docentes, o Governo Federal, em caráter de urgência, criou as Licenciaturas Curtas para formar professores destinados à área de Ciências. Foram muitas as críticas a essa preparação rápida e, assim, diante dos anseios por uma formação condizente com os novos propósitos educacionais, surgiu uma intensa discussão sobre as finalidades dessa formação profissional.

Vale ressaltar que, nas décadas de 1960 e 1970, a decisão de organizar os cursos de licenciatura em Ciências implicava o aprofundamento epistemológico das diferentes áreas do conhecimento científico, conforme as diversas formações disciplinares de nível universitário em torno do movimento de "Ciência Integrada". Depois dessa iniciativa, poucas foram as proposições para o desenvolvimento de cursos de formação de professores de Ciências para o ensino fundamental, já que a maior parte das universidades brasileiras optou por continuar formando licenciados em áreas científicas específicas. Para Wortmann (2003), as discussões sobre os modos de estruturação das áreas de conhecimento da disciplina Ciências Físicas e Biológicas também enfraqueceram, embora esta autora reconheça que, de certa forma, elas foram incorporadas às discussões sobre "interdisciplinaridade", ainda em destaque no cenário educativo brasileiro.

Wortmann (2003) analisou as proposições para a formação de professores de Ciências Naturais contidas em duas propostas organizadas pela UFRGS, durante a década de 1980. À época, Chassot (1990) registra defesas de uma formação docente adequada, pautada na integração de conteúdos para a área de Ciências no ensino fundamental. Conforme acentua:

[...] Parece aceitável que o início da formação científica de uma criança ocorra de uma maneira integrada para que, à medida que ela avance na sua formação, busque uma maior especialização. Assim, é muito provável que uma criança de $5^{\mathrm{a}}$ a $8^{\mathrm{a}}$ série veja $\mathrm{o}$ mundo de uma maneira muito mais integrada do que, por exemplo, um estudante ao final do $2^{\circ}$ grau (Chassot, 1990, p.64).

A justificativa para a integração nessa área de conhecimento é de que ela deveria estar relacionada à realidade vivida pela criança e pelo adolescente, preparando-os para ler o mundo em que estão inseridos e, assim, compreendê-lo e transformá-lo. "Não ensinamos Ciências para fazer cientistas, mas para facilitar o viver. $\mathrm{O} 1^{\circ}$ grau não é para preparar o $2^{\circ}$ grau" (Chassot, 1990, p.65).

7 A ciência integrada prescinde de uma postura teórico-metodológica diante do conhecimento, que se diferencia, simplesmente, do processo de integração curricular. 


\section{O Curso de Licenciatura em Ciências Naturais da Universidade Estadual de Maringá-UEM}

A proposta de se criar uma Licenciatura Plena em Ciências, para formar professores para atuar nas séries de $5^{\mathrm{a}}$ a $8^{\mathrm{a}}$ (hoje do $6^{\circ}$ ao $9^{\circ}$ ano do ensino fundamental), não se efetivou na Universidade Federal do Rio Grande do Sul. O empenho para a criação desse curso deve-se a outras instituições ${ }^{8}$. Abordamos o curso aprovado em 1991 na UEM, em cujo contexto institucional fomos motivadas a realizar a presente pesquisa. Para Carvalho (2001), a criação desse Curso de Licenciatura Plena em Ciências correspondeu a um conjunto de iniciativas dos anos de 1980 e início de 1990 para a expansão do ensino de Ciências em nível nacional, em atenção a diversos interesses locais. Segundo o autor, quando da organização do Projeto Pedagógico desse Curso do Campus Regional de Goioerê CRG - UEM, alguns cuidados teóricos foram tomados. A proposta fundamentou-se no movimento histórico que deu sustentação à demanda pela área de conhecimento Ciências Naturais, com a consequente formação de seus professores. $\mathrm{O}$ resultado de muitas parcerias que se sucederam contou com o amparo teórico de uma equipe de professores da UNICAMP e, posteriormente, do ilustre educador Paulo Freire, que se juntou ao grupo (Carvalho, 2001).

Com respaldo na historicidade das novas demandas de formação de professores, situamos que a proposta desse Curso de Licenciatura em Ciências Naturais está também sujeita a várias leituras e interpretações. Para nos referirmos a esses diferentes significados, lançamos mão da contribuição de Freire e Shor (1986): “[...] O fato é que as relações entre o subsistema da educação e o sistema global da sociedade não são mecânicas. São relações históricas. São dialéticas e contraditórias” (p.49).

Nas discussões ocorridas quando da organização dessa Licenciatura na modalidade plena, enfatizava-se a percepção do conhecimento em processo, nele se incluindo o educador. Este deveria ter uma formação pautada na "Ciência Integrada" e, ao mesmo tempo, estar aberto aos novos saberes que emanam da relação entre os diferentes indivíduos. As preocupações e os cuidados explicitados no Projeto Pedagógico encontraram respaldo nos Parâmetros Curriculares Nacionais, no qual o papel do professor de Ciências está assim definido:

É papel do professor criar oportunidades de contato direto de seus alunos com fenômenos naturais e artefatos tecnológicos, em atividades de observação e experimentação, nas quais fatos e ideias interagem para resolver questões problematizadoras, estudando suas relações e suas transformações, impostas ou não pelo ser humano (Secretaria de Educação Fundamental, 1998, p.58).

Tais propósitos de formação docente também tiveram respaldo legal na Nova LDB 9.394/96:

Art. 1. $\$ 2^{\circ}$ A educação escolar deverá vincular-se ao mundo do trabalho e à prática social (...).

8 Nosso estudo não examinou tais cursos, mas não podemos deixar de mencionar que, atualmente, têm surgido muitas iniciativas para a criação dessa licenciatura, em uma nova edição da licenciatura curta. 
Art. 26. $\$ 1^{\circ}$ Os currículos a que se refere o caput devem abranger, obrigatoriamente, o estudo da língua portuguesa e da matemática, o conhecimento do mundo físico e natural e da realidade social e política, especialmente do Brasil (Lei no 9.394, 1996).

\section{A disciplina Ciências Naturais}

Em decorrência dessas demandas, principalmente partir da década de 1980, a disciplina de Ciências Naturais foi orientada por políticas globais que, no contexto brasileiro, apresentavam-se como um incessante apelo a mudanças, desde conteúdos e encaminhamentos diferenciados até as políticas de formação de professores. No caso específico dessa área de conhecimento, Fracalanza, Amaral e Gouveia (1986) afirmam que muitos avanços se efetivaram, mas, em uma revisão do passado recente desse movimento, os programas normativos padronizados, elaborados por grupos de especialistas, vêm sendo questionados. Acentuam os autores que esse ensino vem sendo avaliado por correntes divergentes:

Há os que propugnam pela definitiva consolidação das linhas de renovação construídas nas décadas anteriores. Outros, por sua vez, empenham-se no sentido do retorno aos modelos do passado, em virtude de se encontrarem desiludidos com o aparente fracasso das propostas de inovação das últimas décadas. Finalmente, há aqueles que têm incentivado uma revisão crítica e profunda de toda essa trajetória de inovação, antes de adotá-la, rejeitá-la ou modificá-la (Fracalanza, Amaral, \& Gouveia, 1986, p.106).

O resultado dos novos encaminhamentos adotados para o ensino de Ciências Naturais também é discutido. Esses autores elencaram sete traços dessas perspectivas de inovação: ensino mais prático; ciência como processo e produto; valorização do conhecimento científico, da ciência e do cientista; ênfase na questão ecológica; valorização do cotidiano do aluno; interdisciplinaridade curricular e, guias e outras formas de padronização e controle. Esses "avanços", para os autores, nem sempre aconteceram conforme o planejado, já que, quando colocados em prática em espaços diferenciados, como o contexto educacional brasileiro, foram modificados segundo as particularidades específicas desses contextos.

Outro aspecto é que os professores nem sempre são preparados para interagir com as mudanças, que são pensadas e incentivadas por especialistas ou que são resultantes de políticas educacionais que não almejam a aprendizagem dos estudantes. Somos, assim, instigados principalmente a considerar que a educação que se propõe a contribuir para o processo de formação humana deve atentar para as características intelectivas dos educandos. Fracalanza, Amaral e Gouveia (1986) acentuam que, sendo direcionado aos adolescentes, o ensino de Ciências Naturais deve ser pautado nas características próprias de raciocínio dessa faixa etária. Segundo esses autores, esses estudantes percebem os objetos em sua totalidade, de forma sincrética. Assim,

[...] pela dificuldade em decompô-lo nas suas partes constituintes e em reconhecer as relações entre essas partes. O seu raciocínio egocêntrico (centrado em si mesmo) também constitui outro fator limitante na percepção do mundo, em vista da dificuldade 
de encarar as coisas de um ponto de vista diferente de si próprio. Entretanto, apesar dessas características, o raciocínio infantil não é algo desorganizado e ilógico, que o adulto e a escola devam rapidamente colocar em ordem. Pelo contrário, possui uma lógica, que é diferente da lógica do mundo adulto e da lógica da ciência [...] (Fracalanza, Amaral \& Gouveia, 1986, p.120).

A complexidade do processo de aprendizagem do ser humano em desenvolvimento foi abordada pelos PCN - Ciências Naturais. Pelo excesso de zelo apresentado na legislação, inferimos a importância de um ensino que permita aos adolescentes o entendimento de seu contexto. Cabe ao conhecimento científico contribuir com elementos para um olhar diferenciado da relação com o social.

Para pensar sobre o currículo e sobre o ensino de Ciências Naturais o conhecimento científico é fundamental, mas não suficiente. É essencial considerar o desenvolvimento cognitivo dos estudantes, relacionando as suas experiências, sua idade, sua identidade cultural e social, e os diferentes significados e valores que as Ciências Naturais podem ter para eles, para que a aprendizagem seja significativa (Secretaria de Educação Fundamental, 1998, p.27).

A questão mencionada nesse documento é de extrema relevância. Com base nela, compõe-se a justificativa para que os conteúdos da área de Ciências Naturais sejam encaminhados com base na integração curricular. Esse discurso foi sistematizado sob diferentes denominações: currículo global; metodologia de projetos; currículo interdisciplinar; currículo transversal. Essas diferentes possibilidades têm apontado encaminhamentos teóricos e práticos em paralelo à organização disciplinar. Essa estrutura curricular tem sido objeto de discussões que vêm sinalizando os limites do conhecimento, quando abordados somente sob o objeto de investigação delimitado pelo espaço disciplinar. Para Japiassu (1976), é "bem verdade que cada disciplina, através de seu enfoque específico, não somente tem a pretensão de fornecer o real, mas o fornece de fato". Dessa constatação, referiu-se aos limites de compreensão da realidade: “No entanto, trata-se de um real sempre 'reduzido' ao ângulo de visão particular dos especialistas em questão. Cada um deles adota um ponto de vista que lhe é próprio para observar, representar e explicar sua realidade: uma dimensão do humano" (p.66).

$\mathrm{O}$ autor apontou várias tentativas de restaurar a unidade do saber, no entanto, “o século XIX veio colocar um fim a essas esperanças de unidade, sobretudo com o surgimento das especializações, verdadeiras cancerizações epistemológicas" (Japiassu, 1976, p.48). Também Santomé (1998) atribuiu aos séculos XIX e XX o período das grandes mudanças no mundo da produção. As revoluções industriais e os processos de transformação das sociedades agrárias incentivaram maiores parcelas de disciplinarização do conhecimento.

$\mathrm{Na}$ atualidade, em decorrência da socialização desse debate, apareceram algumas iniciativas em prolda integração curricular. Sem a pretensão de abordar todas as iniciativas, consideramos o currículo centrado em disciplinas que admite a integração pensada a partir da incorporação de conhecimentos diversos e da inter-relação entre objetivos. 
Nessa lógica, a de que existe uma relação entre os objetivos presentes nos conteúdos que compõe as disciplinas, amparam-se diferentes propostas de interdisciplinaridade, sujeitas a várias interpretações. Consideramos que essa defesa do conhecimento pode permitir a compreensão e o enfrentamento dos problemas sociais e contribuir para o ensino de crianças e adolescentes.

\section{Contexto de produção de textos: discussões sobre formação de professores de Ciências Naturais}

Como expressão do contexto de produção de textos, consideramos a trajetória recente dos cursos de Ciências Naturais, oferecidos no contexto educacional brasileiro. É importante ressaltar que, a partir da reforma estabelecida pela LDB 9394/96, dentre os vários avanços, está a obrigatoriedade da formação em cursos plenos de nível superior para os profissionais da educação (MEC - CNE/CP, 1, 2002). Na LDB atual foram estabelecidos novos rumos para a educação brasileira. A eles se relaciona a organização das diretrizes para orientar os Cursos de Graduação a definir suas diferentes áreas de conhecimento. A finalidade seria promover "a flexibilização na elaboração dos currículos dos cursos de graduação, retirando-lhes as amarras da concentração, da inflexibilidade dos currículos mínimos profissionalizantes nacionais, que são substituídos por 'Diretrizes Curriculares Nacionais"” (MEC - CNE/CES 67/2003, p.8).

Reafirmamos que o fim dos cursos de licenciatura curta não resultou em uma definição de formação específica para os professores de Ciências Naturais. Em consequência, a maior parte das universidades brasileiras prefere continuar formando professores em áreas específicas. Muitos educadores que tomaram a temática do ensino de Ciências Naturais para estudo têm apontado para o problema da indefinição da formação de professores para atuar nos anos finais do ensino fundamental. Nessa mesma linha de discussão, estão as contribuições de Ayres, Lima-Tavares, Ferreira, \& Selles (2008), Magalhães Júnior e Pietrocola (2010) e Imbernon et al. (2011).

As questões investigadas por esses autores referem-se ao processo de formação dos professores para a área de Ciências Naturais e às dificuldades provenientes da formação voltada aos anos finais do ensino fundamental, cuja característica é o encaminhamento teórico-metodológico do ensino integrador. Num constante compromisso com discussões que compreendem a melhoria dessa formação, esses pesquisadores denunciam também a falta de uma identidade própria para o professor de Ciências Naturais. Essa problemática é agravada pelo histórico da área e também pelo fato de não haver uma Diretriz Curricular Nacional específica para esta licenciatura. Nesse contexto, para Imbernon et al. (2011), evidencia-se mais uma vez um ensino de Ciências Naturais com resultados insuficientes e cujo modelo de formação de professores oscila entre a especificidade disciplinar e a generalidade. No Segundo Seminário Brasileiro sobre as Licenciaturas em Ciências Naturais, ocorrido em 2010, na tentativa de contribuir para a sistematização de Diretrizes Curriculares, os participantes sugeriram que os grandes temas que deveriam compor a estrutura curricular dessa Licenciatura deveriam abranger: 
1. Necessidade de se trabalhar as disciplinas pedagógicas desde o início do curso;

2. Necessidade de uma base sólida nas áreas de Química, Física, Biologia e Geociências (Ciências da Terra, Ciência do Universo, Ciências da Vida, Física e Química);

3. O trabalho por meio de eixos temáticos pode propiciar interdisciplinaridade;

4. Os PCNs seriam a referência para organização desses eixos temáticos (Imbernon et al., 2011, p.89).

Com relação ao perfil do professor para atuar em Ciências Naturais, os grupos de trabalho participantes desse Seminário registram que esse profissional deveria:

Ser educador; Visão crítica, inovadora; Estímulo ao diálogo; Formação mais abrangente, qualitativa, com capacidade de dialogar com as diferentes disciplinas, sem ser um especialista; Olhar para/com o sujeito; Despertar a curiosidade; Capacidade de selecionar informações e transformá-las em conhecimento confiável e adequado a diferentes níveis de escolarização; Pensar na atividade pedagógica de forma investigativa (professorpesquisador); Compromisso social; Capacidade de propiciar o debate aos estudantes em torno de questões sócio-científicas; Compreender as grandes ideias estruturadas em áreas de Química, Física, Biologia, Astronomia e Geociências; Figura estratégica para promoção da educação Ambiental; Autogestão do aprendizado; sensibilizar-se pelas questões legais acerca de seu papel como professor e pelas questões da infância, adolescência; Propiciar aos alunos o desenvolvimento de atividades investigativas; Aplicação do conhecimento no cotidiano; Capaz de discutir a natureza, ambiente, sociedade, tecnologia; Trabalhar com atividades formais, não formais e informais (Imbernon et al., 2011, p.87-88).

O teor desse encontro e de muitos outros que têm acontecido, muitas vezes sem divulgação, demonstra que, apesar da ampliação do número de Cursos de Licenciaturas em Ciências Naturais por todo o país, esse movimento vem ocorrendo sem um diálogo articulador entre seus organizadores. Nesse sentido, registra-se a falta de espaços físicos e de agendas pontuais para se discutir e investigar meios que promovam avanços na questão. A extinção dos cursos de licenciatura curta e a manutenção de cursos de licenciatura integrada (de duração plena) demonstram que a produção de políticas educacionais é uma atividade complexa, um processo instável, em razão da correlação de forças. Conforme Ball (2001a), "as políticas são articuladas tanto para obter efeitos materiais quanto para produzir apoio para esses efeitos" (p.129).

Nosso compromisso é compreender as razões da ausência dessa Diretriz Curricular Nacional, como uma forma de contribuir para as discussões em torno do perfil do professor que venha a atender as características de educação apontadas como necessárias à integração curricular, para a disciplina de Ciências Naturais. A realidade educacional que norteou o ensino dessa disciplina foi influenciada pela definição de novos rumos da educação. Ball (2001a) enfatiza que a elaboração de políticas nacionais é resultado das ideias pensadas em outros países e experimentadas na realidade local. A maior parte das políticas são montagens modificadas “[...] através de complexos 
processos de influência, de produção de textos de disseminação e, em última análise, de recriação do contexto da prática” (p.132).

\section{Contexto da prática: características de formação de professores de Ciências Naturais}

Para discutir iniciativas de formação com características voltadas para o perfil desse professor, abordamos as propostas curriculares anteriormente citadas. Os excertos dos discursos das propostas curriculares receberam a numeração que identifica tanto os Cursos de Licenciaturas em Ciências Naturais quanto os Cursos de Licenciaturas em Ciências Biológicas (Proposta 1: USP; Proposta 2: UEM e Proposta 3: UNIRIO). As referências às Propostas Curriculares são: Licenciatura em Ciências Naturais: LCN e Licenciatura em Ciências Biológicas: LCB. Para os Parâmetros Curriculares usamos: PCN - Ciências Naturais.

Consideramos que as Propostas Curriculares e as falas dos professores entrevistados expressam os diversos aspectos educacionais que os contextos solicitam. Procuramos não perder de vista os anseios de educação no sentido de proporcionar aos estudantes condições para que se posicionem com relação à vida individual e coletiva.

Para avançar no diálogo, parece-nos necessário pontuar o encaminhamento da categoria interdisciplinaridade ${ }^{9}$ que, de nosso ponto de vista, respalda a integração curricular. Com o subsídio do "ciclo de políticas", articularemos essa categoria aos diferentes contextos. Consideramos que o contexto de influência promove diferenciadas produções de textos, que se manifestam no contexto das práticas.

\section{Articulações com a categoria interdisciplinaridade} de LCN.

Os seguintes excertos sobre a interdisciplinaridade encontram-se nas propostas

Os guias curriculares oficiais têm como ideia inovadora a centralidade de temas transversais e geradores, de eixos norteadores, de conceitos nucleares e/ou de projetos interdisciplinares. Eles são elaborados a partir de avanços teórico-conceituais da área educacional e em função das políticas públicas adotadas em nível governamental [...] Formar recursos humanos de alto nível para atuar no ensino de ciências no nível fundamental, valorizando a compreensão interdisciplinar dos fenômenos naturais e a capacidade de difundir o conhecimento científico como as características dos egressos (Proposta 1, p.8-10).

Dessa forma, admite diversidade de conhecimentos, inclusive o saber popular, visando promover uma visão crítica, fomentar o trabalho interdisciplinar e, sobretudo, transformar o aluno de agente historicamente passivo, receptor, num cidadão transformador da sociedade (Proposta 2, p.11-12).

9 Comungamos do entendimento de que interdisciplinaridade e integração curricular não são sinônimos. Conforme Aires (2011), a "Interdisciplinaridade parece estar mais relacionada com a epistemologia das disciplinas científicas, com o ensino superior e a pesquisa, enquanto que a Integração Curricular parece estar mais relacionada com a epistemologia das disciplinas escolares, com o ensino médio e fundamental" (p.225). 
Em se tratando do conhecimento identificado nos vários campos disciplinares, que tem respaldado a estrutura curricular do ensino de Ciências Naturais, vale ressaltar que, como a ciência contemporânea tem vivenciado um processo de ruptura, ela vem gerando um rompimento de barreiras disciplinares e a necessidade de se articular a complexidade dos diferentes objetos. No enfrentamento dessa questão, dá-se ênfase ao estabelecimento de um diálogo entre os diferentes conhecimentos. Entendemos que esse diálogo foi o que subsidiou a defesa da interdisciplinaridade em duas, das três Propostas de LCN em análise. Nessas propostas, enfatiza-se a ideia inovadora presente nos guias curriculares, nos quais são sugeridas a criação de projetos interdisciplinares e a transformação do aluno passivo e receptor em um cidadão transformador da sociedade. Nas Propostas de LCB não se encontram menções ao trabalho interdisciplinar.

O discurso que aponta uma perspectiva interdisciplinar no Brasil consolidouse na proposta de socialização do conhecimento, na década de 1970, como a de Ivani Fazenda $^{10}$, que não destoou de um discurso oficial em curso. A autora aponta para a necessidade de definições teóricas que propiciem a eliminação de obstáculos à efetivação da interdisciplinaridade, dentre os quais pontua os de ordem epistemológica e institucional; psicológicos e culturais; metodológicos; de formação pedagógica e materiais. Constata, portanto, a ausência de um consenso conceitual, assim como sua indevida utilização. Ela observa que o currículo estruturado em matérias dificulta o trabalho interdisciplinar porque "a estrutura linear em si já é uma forma de provocar a 'compartimentização' do saber em conteúdos estanques”. Por isso, considera necessário eliminar as barreiras entre as disciplinas, não como mera formalização, mas como engajamento entre as pessoas. "A interdisciplinaridade então, depende de uma mudança de atitude frente ao problema do conhecimento, da substituição de uma concepção fragmentária pela concepção unitária do ser humano" (Fazenda, 2002, p.89-97).

Para Veiga-Neto (2010), a pesquisa desenvolvida por Fazenda surgiu num momento propício: visando redirecionar os propósitos da educação, discutiam-se questões epistemológicas e pedagógicas fundamentais. Segundo levantamento na área educacional, os textos produzidos durante os anos de 1980 a 1995 foram significativos para a educação e "quase todos fazem referência ao livro de Fazenda ou, pelo menos, a algum outro livro ou artigo da pedagoga". Afirma o autor: "pode-se creditar a ela a emergência e o fortalecimento do movimento pedagógico pela interdisciplinaridade no país" (p.8).

Bianchetti e Jantsch (2002) acentuam que com a diversificação das explicações dos elementos que interferem na sistematização do conhecimento, a partir dos anos de 1990, "desloca-se o eixo explicativo do campo da moral e do voluntarismo para o momento histórico na sua totalidade" (p.21). Nesse sentido, a fragmentação do saber deve ser compreendida além da vontade do sujeito ou de grupos, pois há uma dinâmica histórica que tem sustentado determinadas formas de conhecimento. Considerando

10 Apesar de o contexto brasileiro ter sido influenciado por uma diversidade de produções, com vários enfoques diferenciados da interdisciplinaridade, abordaremos o de Ivani Fazenda, com respaldo nos trabalhos de Hilton Japiassu. 
que a interdisciplinaridade é uma discussão que demanda muito empenho, Veiga-Neto (2010) destaca que uma correta exploração desse conceito implicaria:

a) um maior diálogo entre professores, alunos, e pesquisadores de diferentes áreas do conhecimento; b) o melhor preparo profissional e uma formação mais integrada do cidadão; c) uma ciência responsável, já que seria possível trazer a problematização ética para dentro do conhecimento científico; d) a reversão da tendência crescente de especialização, de modo que se desenvolveria uma visão holística da realidade; e) a criação de novos conhecimentos, graças à fecundação mútua de áreas que até então se mantinham estanques; f) a reversão de um suposto desequilíbrio ontológico de que padeceria a Modernidade, isto é, a reversão do descompasso entre uma pretensa natureza última das coisas e as ações humanas que vêm alterando tal natureza ao longo dos séculos (Veiga-Neto, 2010, p. 9).

As riquezas desses argumentos nos instigam a ponderar qualquer atitude infundada, seja teórica ou prática. A partir da diversidade de abordagens, algumas posições têm sido registradas sobre o papel da educação corporificado nos currículos. A exemplo, os PCN - Ciências Naturais propõem a contextualização das disciplinas científicas e o estabelecimento de uma inter-relação que promova uma interdisciplinaridade possível:

[...] diferentes propostas têm sugerido o trabalho com temas que dão contexto aos conteúdos e permitem uma abordagem das disciplinas científicas de modo interrelacionado, buscando-se a interdisciplinaridade possível dentro da área de Ciências Naturais (Brasil, 1998, p.27).

Enfatizamos que esse documento, não destoando de tantos outros textos, resultantes de iniciativas em prol da articulação dos saberes, atentou para uma interdisciplinaridade "possível". Essa observação sinaliza para a grande dificuldade que norteia esse encaminhamento metodológico, mencionada na fala dos professores:

[...] a questão da interdisciplinaridade é, ela é muito falada, muito conceituada e, ao mesmo tempo, existe uma dificuldade dessa conceitualização se concretizar, porque a grande questão é: muitos autores compreendem a interdisciplinaridade como uma relação entre as disciplinas e, no caso da área das Ciências da Natureza, se considera como Ciências da Natureza e, dentro, a disciplina de Física, Química e Biologia, mas como área, então tem que ter algum diálogo e, eu penso que o diálogo dentro da área vai passar por um diálogo conceitual, onde é preciso compreender os conceitos que são interdisciplinares e os conceitos que são disciplinares [...] (PB).

[...] também é uma discussão, de longa data, eu me lembro na década de oitenta, nós trabalhamos muito intensamente na perspectiva interdisciplinar, eram muitos estudos, muitas práticas, muitas análises. E não... e nada parece que... então era difícil de acontecer. Então, o que é que nós percebíamos? Que acabava naquela justaposição de áreas [...] invariavelmente, você cai naquela questão que... eu acho que não houve um entendimento ainda de que... o que é essa tendência interdisciplinar. Enquanto não houver isso, e os grupos não discutirem nessa... [...] (PQ). 
A mãe da interdisciplinaridade, ou o pai, é o contexto. Quando você está no contexto, o contexto é interdisciplinar. Então, pega qualquer coisa, pega o animal doméstico, o gato, o cachorro, ou o papagaio ou o pombo. Com o qual se convive, não necessariamente o doméstico mas os animais urbanos. Uma coisa é olhar esse bicho numa perspectiva zoológica ou biológica, classificação, espécie etc. [...] O conhecimento humano continua disciplinar, mas é quando eu trago para o contexto que a interdisciplinaridade aflora como coisa natural, não como invenção artificial (PF).

Mesmo que essa dificuldade seja reconhecida, o trabalho interdisciplinar tem sido visto como uma possibilidade de articulação dos diferentes campos de saber. Essa condição representaria um aprofundamento do conhecimento. Nas falas dos professores entrevistados aparece a ênfase na integração entre as diferentes disciplinas, Física, Química e Biologia, como uma forma de compor a área das Ciências da Natureza. Essa relação seria estabelecida por meio de um diálogo conceitual que tende a discernir quais conceitos são disciplinares e quais são interdisciplinares. A dificuldade é exatamente como estabelecer esse diálogo, já que as condições atuais das práticas educativas dificultam iniciativas diferenciadas, assim como a própria sistematização de sua socialização.

Acentuamos que os anseios dessa iniciativa de ensino residem na educação básica, uma vez que as instituições superiores não têm oferecido uma formação que favoreça esse entendimento. Outra necessidade observada pelos entrevistados para a promoção da interdisciplinaridade é tomar o contexto como referência. A defesa da valorização do contexto do estudante não é nova, mas tem se acentuado, principalmente a partir da década de 1980, quando o aluno foi chamado a participar do discurso ético que norteia os propósitos do conhecimento científico. Essa tendência, ao mesmo tempo em que somou esforços, responsabilizou todos os indivíduos pelos resultados dos avanços científicos, que, em muitos casos, são contraditórios.

Essa ênfase também aparece nos PCN - Ciências Naturais, nos quais se considera importante o estabelecimento da relação da teoria com situações práticas: "o estudo das Ciências Naturais de forma exclusivamente livresca, sem interação direta com os fenômenos naturais ou tecnológicos, deixa enorme lacuna na formação dos estudantes" (Secretaria de Educação Fundamental, 1998, p.27). Chama-se a atenção para as interrelações necessárias para a promoção da aprendizagem do estudante. Tal necessidade é confirmada nas Diretrizes Curriculares Nacionais para a Educação Básica. Conforme o trecho sobre as formas de organização curricular, Art. 13, Parágrafo 3 - Inciso III,

[...] escolha da abordagem didático-pedagógica disciplinar, pluridisciplinar, interdisciplinar ou transdisciplinar pela escola, que oriente o projeto políticopedagógico e resulte de pacto estabelecido entre os profissionais da escola, conselhos escolares e comunidade, subsidiando a organização da matriz curricular, a definição de eixos temáticos e a constituição de redes de aprendizagem (Resolução CNE/CEB 4 de 13 de julho de 2010, 2010).

Esse cuidado com um encaminhamento teórico-metodológico comprometido com a apropriação do conhecimento aparece tanto na legislação quanto nas propostas 
de LCN, as quais apontam para um avanço teórico significativo em relação ao ensino. Conforme o exposto, a intenção se confirma:

A base comum nacional (LDB), definida no documento da Conae 2010, deve voltar-se para a garantia de uma concepção de formação pautada tanto pelo desenvolvimento de sólida formação teórica e interdisciplinar em educação de crianças, adolescentes, jovens e adultos (as) e nas áreas específicas de conhecimento científico quanto pela unidade entre teoria e prática e pela centralidade do trabalho como princípio educativo na formação profissional, como também pelo entendimento de que a pesquisa se constitui em princípio cognitivo e formativo e, portanto, eixo nuclear dessa formação (Parecer, 2/2015, p.7-8).

Os documentos oficiais agregam diferentes propósitos de formação e diferentes intenções que vêm amparando o ensino de Ciências Naturais. Também as novas Diretrizes Curriculares Nacionais para a formação de professores contêm orientações nesse sentido:

Art. 5. A formação de profissionais do magistério deve assegurar a base comum nacional [...] que se leve em conta a realidade dos ambientes das instituições educativas da educação básica e da profissão, para que se possa conduzir o (a) egresso (a): I à integração e interdisciplinaridade curricular, dando significado e relevância aos conhecimentos e vivência da realidade social e cultural, consoantes às exigências da educação básica e da educação superior para o exercício da cidadania e qualificação para o trabalho [...] (Parecer CNE/CP 2 de 2015, 2015).

O que vai sendo evidenciado é que, contraditoriamente aos avanços das especializações, o conhecimento científico tem sido abordado cada vez mais como inter-relação. Segundo Lopes (2008a), essa direção visa a resolução de problemas sociais complexos, no "processo de constante associação de conteúdos disciplinares a suas tecnologias". Em consequência, "se as ciências não mais se desenvolvem de modo fragmentado, cabe à escola reorganizar seu conhecimento de maneira a responder às mudanças das ciências e preparar os alunos para uma forma mais adequada de lidar com os saberes necessários à solução de problemas" (p.44). Essa direção vem apontando para a integração dos conteúdos subsidiada pelo trabalho interdisciplinar.

$\mathrm{Na}$ contramão da objetivação da prática social, pautada unicamente no poder, muitos educadores tem defendido a participação dos indivíduos nessas estruturas, o que seria possível por meio do domínio de diversos campos do conhecimento. Chassot (1998) chama a atenção para as tessituras da ciência, cujo processo

[...] é muito mais produtivo se for uma construção solidária, envolvendo colegas de diferentes áreas do conhecimento ao invés de algo solidário. É muito provável que nessa atividade solidária haja deslumbramentos ao se descobrir as diferentes tessituras que compõem a construção do conhecimento e de quanto cada uma das diferentes ciências, ainda, busca a expansão dos conhecimentos [...] (Chassot, 1998, p.91).

Esses aspectos e conceitos são veiculados e impulsionados por um discurso híbrido que o currículo tem agregado. Em consequência, o currículo também tem 
se pautado em um movimento que aponta para a possibilidade de novos saberes. $\mathrm{O}$ que observamos nos discursos é que a defesa da interdisciplinaridade se impôs. Nesse sentido, os avanços na produção do conhecimento têm acentuado a possibilidade da integração curricular. Esse discurso está presente nas propostas analisadas.

\section{Articulações com a categoria Integração Curricular}

Os seguintes excertos encontram-se nas propostas dos cursos e demonstram a presença desta categoria nas referidas propostas.

Propostas de LCN:

Este conjunto de conhecimentos integrados das Ciências da Natureza (ciências da Terra, da vida, astronomia, física e química) e da matemática é essencial para promover uma nova relação do ser humano com a natureza, contribuindo à formação de cidadãos críticos e responsáveis com relação à ocupação do ambiente e utilização de seus diversos recursos naturais [...] (Proposta 1, p.11).

Disciplinas e atividades ligadas à Sociologia, Antropologia, História e Filosofia da Ciência, dão alicerces para a integração humanística.

Pelo menos 272 horas de trabalho na disciplina de Projetos CTS (Ciência, Tecnologia e Sociedade) assegurará ao longo dos dois últimos anos do curso, a integração entre parte humanística e a base científica, apoiando-se nas disciplinas pedagógicas (Proposta 2, p.11).

[...] a abordagem integrada dos diversos aspectos da Natureza é fundamental à formação dos cidadãos conscientes, responsáveis, capazes de emitir julgamento sobre as atividades da Sociedade no uso e ocupação do ambiente, o que já é percebido e solicitado pelo mercado de trabalho; consequentemente, já há demanda por esta formação. $\mathrm{O}$ licenciado em Ciências da Natureza tem formação para lecionar Ciências na $1^{\text {a }}$ e na $2^{\text {a }}$ etapas do ensino fundamental e ainda, no ensino médio [...] Sintetizando, com todos os conteúdos das disciplinas e atividades de estágio e laboratório realizados durante o curso, o Licenciado em Ciências da Natureza estará preparado para orientar alunos, através de atividades teóricas e práticas, a adquirirem um conhecimento integrado da Natureza [...] propõe curso para a formação de professores de Ciências, com um projeto pedagógico alicerçado através de um currículo e sequência de atividades de formação, que permitirão formar educadores com uma visão ampla e integrada das Ciências da natureza [...] (Proposta 3, p.9-11).

Propostas de LCB:

O curso de Ciências Biológicas [...] tem como objetivo formar biólogos (licenciados ou bacharéis), através de um currículo abrangente e integrado, com visão generalista de todos os níveis de organização biológica [...] É necessário que, além da Biologia, este profissional conheça a realidade sociocultural do país e de sua região em particular, para que o ensino dessa Ciência e os resultados das pesquisas biológicas sejam aproveitados e aplicados em função dessa realidade. O biólogo deve desenvolver o raciocínio científico 
e o espírito crítico integrados à natureza e à cultura de seu povo (Proposta 2, s/p).

Verificamos que a defesa da integração curricular está contida nas três propostas de LCN, as quais estão em consonância com o entendimento de que as Ciências da Natureza existem de forma integrada. Tais propostas apontam também para a necessidade de se integrar a base humanística à base científica por meio das disciplinas pedagógicas e da filosofia, o que proporcionaria uma visão ampla do conteúdo. Apenas uma proposta de LCB contém referência à integração curricular, mas de uma forma abrangente, pautada na visão generalista da organização biológica.

Já nos PCN - Ciências Naturais, a menção à possibilidade de integração prescinde tanto da interação entre teoria e prática quanto da integração do conhecimento. A visão de mundo contida nesse documento é a necessidade de se formar um olhar para "[...] um todo formado por elementos inter-relacionados, entre os quais o ser humano, agente de transformação [...] Os eixos temáticos representam uma organização articulada de diferentes conceitos" (Secretaria de Educação Fundamental, 1998, p.35).

Nas falas dos professores, a defesa da integração curricular aparece na valorização de conceitos imbricados e do estabelecimento de relações mais amplas. Nessa valorização estaria a possibilidade de compreensão do conhecimento veiculado na sociedade, já que o professor seria instigado a buscar possibilidades, a fazer leituras diferenciadas, pautando-se em várias interpretações da realidade. Conforme os professores acentuam:

[...] a minha perspectiva de estudos e análise é numa perspectiva dos conceitos que logicamente muitos estão imbrincados, ligados a conteúdos, mas que têm alguns conceitos que transcendem [...] então quando a gente começa a pensar essas relações conceituais mais amplas consegue fazer um novo trabalho pra possibilitar a compreensão do mundo de hoje... então dos tecnológicos, científico. Quais são as demandas sociais desses conhecimentos? Sem ter um conjunto de conceitos [...] (PB).

[...] Mas, se ele tem que ser inter, não tem jeito. O professor tem que buscar.... não adianta.... mesmo que seja... digamos que tivéssemos uma realidade que tivesse um professor de cada conteúdo desse no ensino fundamental: um de Física, um de Química, um de Biologia, digamos assim, mesmo assim, lidar com os fenômenos mais macro.... de forma que ele possa ler o mundo, que ele pegue uma garrafa de água mineral e ele saiba interpretar isso [...] (PQ).

[...] Então, você tem que ensinar ciência como linguagem, ciência e tecnologia tem que te dar instrumento para as decisões práticas e tem que promover também visão de mundo, saber se situar no cosmos, saber que quando você olha para o céu quase tudo que você está vendo ali são estrelas da Via Láctea [...] (PF).

Podemos considerar que, em sua complexidade, as relações que envolvem o conhecimento e sua seleção são muitas vezes condicionadas aos propósitos sociais e, assim, ora apontam para mudanças ora para a perpetuação de conteúdos e valores que são considerados imprescindíveis à sustentação de um determinado modelo de sociedade. É nesse contexto que, para Lopes (2008), defende-se a integração curricular. 
Esta,

[...] relaciona-se com o entendimento de que, no contexto do paradigma pós-fordista, há necessidade de formação de habilidades e competências mais complexas e superiores, as quais seriam mais facilmente desenvolvidas em uma perspectiva integrada. Igualmente, é entendido que a produção do conhecimento é cada vez mais integrada e, assim sendo, as pessoas precisam ser formadas para trabalhar nessa 'nova' maneira de produzir conhecimentos (Lopes, 2008, p.33).

Nesse sentido, junto com os pressupostos teóricos que fundamentam a integração curricular, estão as defesas discursivas da necessidade da ciência integrada. Essa característica epistemológica do conhecimento é que foi defendida para subsidiar o currículo das Ciências Naturais dos anos finais do ensino fundamental, mas não houve avanços nesse sentido, apesar de movimentos sociais terem dado sustentação à sistematização da disciplina de Ciências Naturais. A ausência de pesquisas expressa as posturas tomadas por comunidades disciplinares, mostrando que estas não se empenharam para isso. De nossa perspectiva, as comunidades curriculares são capazes de produzir sentidos diversos para as políticas porque influenciam não somente o contexto da prática, mas também aqueles que "atuam na produção das políticas curriculares", na forma de "importantes mediadores dessas políticas entre os grupos disciplinares nas escolas". Quanto aos grupos disciplinares: “[...] por mais que pertençam ao campo educacional acadêmico e constituam relações em função do posicionamento nesse campo, identificam-se com as disciplinas escolares, na medida em que constroem seus objetos de pesquisa com base nessas disciplinas" (Lopes, 2004, p.50).

Consideramos também que o discurso que apresentou a integração curricular fazia parte de um momento em que os campos científicos da pesquisa disciplinar se consolidavam. As defesas da ciência integrada prescindiam de uma opção teóricometodológica de investigação. Em razão dos interesses grupais e pessoais da pesquisa disciplinar em nível superior, os avanços na ciência integrada que poderiam dar respaldo à interdisciplinaridade não aconteceram. Em decorrência, a organização curricular na área de Ciências Naturais, cuja característica é a do conhecimento generalizado, sistematizou-se com base na junção de disciplinas. Essa estrutura curricular da disciplina de Ciências Naturais recebeu muitas críticas.

O exercício teórico respaldado no "ciclo de políticas" é significativo para essa discussão. É nesse contexto que o perfil desse profissional, no qual coexistem diferentes competências, vai sendo definido. Enfatizam-se as ações teórico-metodológicas de que a prática docente é resultado de competências individuais, de que a ela cabe a responsabilidade pela aprendizagem do educando. Com esse olhar, reproduzimos um trecho do artigo 13, Parágrafo $\$ 3$. Inciso VIII das Diretrizes Curriculares Nacionais para a Educação Básica, no qual se encontra uma referência às formas de organização curricular.

Constituição de rede de aprendizagem, entendida como um conjunto de ações didático-pedagógicas, com foco na aprendizagem e no gosto de aprender, subsidiada 
pela consciência de que o processo de comunicação entre estudantes e professores é efetivado por meio de práticas e recursos diversos (Resolução CNE/CEB 4 de 13 de julho de 2010, 2010).

Com base nesses diversos elementos, podemos afirmar que a definição de um perfil de professor voltado para o ensino de Ciências Naturais não é simples.

\section{Articulações com o perfil docente desejado}

Propostas de LCN:

1. Formação docente voltada para a promoção de mudanças curriculares efetivas. Concepção ampla de currículo, que envolva não somente o currículo escrito, mas também o currículo em ação. 2. Formação docente voltada para a resolução de ambiguidades ou contradições na identidade da própria formação docente [...] O profissional egresso do curso de LCN estará preparado para promover, nas escolas, a formação de cidadãos conscientes e críticos [...] (Proposta 1, p.7-12).

[...] qualificação do professor de Ciências, como ator do processo de fazer Ciência, valorizando sua capacidade criativa, estimulando a vontade de descoberta e desenvolvendo sua capacidade crítica (Proposta 2, p.8).

[...] formação de professores com visão mais abrangente das Ciências da Natureza [...] possuidores não só de uma compreensão das relações entre os processos, e, portanto, os conceitos físicos, químicos e a Natureza, tanto na sua expressão biológica como em sua expressão inanimada, mas também de estratégias e espírito de busca de estratégias para facilitar a apreensão, pelos alunos, do funcionamento da Natureza como um todo. Profissionais formados neste contexto poderão exercer na plenitude a cidadania, e a escola contribuirá concretamente para formar cidadãos conscientes, críticos, com responsabilidade econômica, social e ambiental [...] será preparado para estimular os alunos em sua curiosidade científica, incentivando-os à pesquisa e à reflexão ética perante a sociedade e a natureza [...] (Proposta 3, p.9-11).

Propostas de LCB:

[...] formar profissionais que se dediquem ao ensino e/ou à pesquisa nessa área de conhecimento, bem como formar profissionais capacitados a tratar dos problemas ambientais de maneira integrada, devendo sua atuação na preservação e no monitoramento dos ecossistemas assumir um caráter essencialmente holístico (Proposta $2, \mathrm{~s} / \mathrm{p})$.

As intenções de formação do professor para atuar na disciplina de Ciências Naturais dos anos finais do ensino fundamental são amplas. Particularmente, os propósitos para a formação docente apresentados nas propostas de LCN vão ao encontro das conhecidas mudanças teórico-metodológicas em curso. Cabe salientar o aspecto positivo dessa ousadia teórica: buscar saídas para o impasse da socialização do conhecimento que se consolidou historicamente. No entanto, vale registrar que o avanço do saber é fruto de pesquisas disciplinares, focadas em objetos específicos, ao passo que sua propagação e 
a consequente apropriação perpassam a questão da interdisciplinaridade que faz parte da defesa da integração curricular. Em que pese a contradição que envolve essa questão, podemos inferir avanços nas intenções de formação e, mesmo cientes da distância que muitas vezes existe entre o que é planejado e o que acontece na prática em relação aos objetivos definidos, não podemos desprezar a proposta curricular escrita.

Quanto a essa relação, as intenções de formação presentes nas propostas de LCN chamam nossa atenção. Nessas propostas, foram enfatizadas a concepção ampla de currículo e a formação de um professor que promova mudanças, que seja um ator no processo de fazer ciência e tenha capacidade criativa e visão abrangente das Ciências da Natureza. Com essa compreensão da realidade, ele deve buscar estratégias para facilitar a apreensão pelos alunos do funcionamento da natureza como um todo. O ensino deve contribuir para que os alunos sejam agentes de transformação e também sejam estimulados em sua curiosidade científica. Dessa forma, se promoveria a formação de cidadãos conscientes e críticos, capazes de emitir julgamento sobre ações humanas e relacioná-las à natureza, ao ambiente, e à tecnologia.

Dentre as propostas de LCB, apenas uma faz referência à formação de professores que se dediquem ao ensino e à pesquisa na área de seu conhecimento, ou seja, na área biológica, e também que se tornem capacitados a tratar os problemas ambientais de maneira integrada. Vale salientar que as propostas de LCB não mencionam a intenção de formar um perfil docente voltado às necessidades de formação do ensino de Ciências Naturais para os anos finais do ensino fundamental.

As propostas de LCN, comprometidas com um discurso em andamento, apesar de não terem a base teórica de sua Diretriz Curricular Nacional específica, não destoaram quanto ao perfil profissional requerido pelas Diretrizes Curriculares Nacionais. Segundo tais Diretrizes, dever-se-ia promover

[...] um processo contínuo, autônomo e permanente, com uma sólida formação básica e uma formação profissional fundamentada na competência teórico-prática, de acordo com o perfil de um formando adaptável às novas e emergentes demandas [...] na direção de uma sólida formação básica, preparando o futuro graduado para enfrentar os desafios das rápidas transformações da sociedade, do mercado de trabalho e das condições de exercício profissional [...] (Parecer, 67/2003, p.5-6).

Esse é o ideal de formação proposto em um momento de contradição, tanto do conhecimento, quanto das intenções de formação. Pautado em competências e por meio de uma roupagem renovada, o perfil proposto não destoa da intenção de formar o indivíduo para atender às necessidades sociais.

Os professores entrevistados contribuem para traçar o perfil do docente para atuar na disciplina de Ciências Naturais dos anos finais do ensino fundamental:

[...] Se o conhecimento das Ciências da natureza abrange Astronomia, Geologia, Química, Física, Biologia, Matemática, Sociologia, também importante, História, tantas outras coisas que podemos colocar aqui. Então, o que é que precisa? Precisa que o sujeito tenha os conhecimentos de todas essas áreas, mas não é a profundidade do 
conhecimento de cada dessas áreas. Ele tem que saber os conceitos fundamentais de cada uma dessas áreas e as possíveis articulações [...] (PB).

Ou você tem o profissional com essa visão mais integrada, das Ciências, e ele tem que ter um curso que tenha uma boa base de Química, de Física e de Biologia, sempre na perspectiva integradora [...] o curso tem que pensar numa abordagem integradora, voltada mesmo pro ensino fundamental, é... esse é um perfil que eu vejo (PQ).

Ele tem que saber que é professor de gente, ele não é um professor disso ou daquilo. A meta formativa dele é o ser humano diante de si. Então, pra isso ele tem que ter já essa atitude, quer dizer eu tô trabalhando com crianças e jovens, no caso fundamental II, já está em plena puberdade pra adolescência [...] Não é só o conhecimento que ele domina. É a forma com que ele vai lidar com isso e como é que ele vai lidar com aspectos essenciais ligados com higiene, com sexualidade e com tudo o mais [...] (PF).

Em sua riqueza, esses excertos apontam um perfil docente que não destoa do propósito que vem dando sustentação à disciplina Ciências Naturais: a integração curricular. Defendendo esse encaminhamento teórico, consideramos que a perspectiva que relaciona conhecimento e concepção teórico-metodológica está em consonância com as necessidades de formação do estudante, tendo em vista a faixa etária correspondente a essa etapa de ensino.

As discussões em curso têm apontado para o entendimento de que o perfil do professor para atuar na disciplina Ciências Naturais dos anos finais do ensino fundamental deve atender os propósitos de formação que essa área requer. Essas intenções foram confirmadas com as percepções dos professores entrevistados, que também representam o contexto da prática, consolidada tanto nas intenções de formação docente quanto nas experiências educacionais que emanam do envolvimento com a área de conhecimento de Ciências Naturais.

\section{Conclusões}

Iniciando estas considerações, pontuamos que não há conclusão para um assunto que representa a caminhada de tantos envolvidos, especialmente no que tange a área de Ciências Naturais. Neste texto, o objetivo foi dialogar com as características que o professor deve ter para atuar na disciplina de Ciências Naturais e, assim, contribuir com o processo de educação. Seguindo a opção teórico metodológica de que se deve indicar as razões históricas que influenciam o contexto das políticas públicas educacionais, encontramos respaldo na abordagem do "ciclo de políticas" e discutimos a formação dos homens em atenção aos anseios educacionais, que muitas vezes têm se guiado por questões econômicas em detrimento dos propósitos sociais.

Quanto ao contexto de influência, consideramos o movimento cultural que promove os discursos que orientam as políticas educativas em nível nacional. Nesse movimento, situamos a área de Ciências Naturais que se constituiu como uma demanda educacional no início da segunda metade do século XX. Esse momento foi marcado 
pelos avanços do conhecimento científico e pela necessidade de sua socialização para as diferentes classes sociais. Não desconsiderando os aspectos políticos e ideológicos que impulsionaram essa necessidade de expansão do saber, acreditamos que esse acesso tende a contribuir para o processo de formação intelectual e emancipatória do ser humano.

Quanto ao contexto da produção de texto, abordamos o movimento contraditório entre o avanço da socialização do saber e a prática educativa já consolidada. Os diferentes elementos foram definindo os rumos tomados pela disciplina de Ciências Naturais. Dentre os avanços teóricos propagandeados como necessários para atender seus diferentes propósitos está a integração curricular com respaldo na ciência integrada. Esta, que poderia subsidiar a interdisciplinaridade, por razões de interesses diversos, não aconteceu. Em decorrência, a organização curricular na área de Ciências Naturais sistematizou-se com base na junção de disciplinas.

No contexto da prática, que representa esse movimento de relações e interesses, situamos as Propostas Curriculares de Licenciatura em Ciências Naturais e Ciências Biológicas que formam o professor para atuar nas Ciências Naturais. Entendemos que tais propostas estão respaldadas na reforma educacional, que orienta as finalidades sociais de educação com subsídios teórico-metodológicos na integração curricular. Compõem esse contexto também a legislação para a educação básica e a formação de professores, além das entrevistas concedidas por professores, assim como demais produções de autores diversos.

Nossa leitura dos documentos oficiais nos leva a destacar sua vertente híbrida, uma vez que eles sinalizam diferentes propósitos de formação. Entendemos que eles comungam a defesa de que o conhecimento é tema central no currículo e este agrega tanto críticas quanto propostas para a educação emancipatória. Em específico, os PCN - Ciências Naturais sinalizam a adoção de encaminhamentos teórico-metodológicos que deem conta dos anseios de diversidade humana. Neles se leva em consideração os diferentes encaminhamentos para a integração do conhecimento.

Apesar de não haver Diretrizes Curriculares Nacionais para orientar as propostas de LCN, estas não destoaram dos propósitos de formação requeridos para a área de conhecimento. Observamos nelas o compromisso com o conhecimento em constante mudança e com a ciência em processo. Também há a ênfase em formar um professor que compreenda as diferentes manifestações do saber e suas inter-relações e que contribua para a aprendizagem do estudante em desenvolvimento. Nelas se apresentam também a defesa do conhecimento inter-relacionado e a atenção para os aspectos da integração curricular com respaldo teórico no trabalho interdisciplinar.

Quanto às propostas de LCB analisadas, fica explícita a opção teóricometodológica por um conteúdo que tenha respaldo epistemológico nas Ciências Biológicas. Nesse sentido, a integração curricular aparece somente no que se refere à organização biológica. Não encontramos menção à interdisciplinaridade. Em suma, tais Propostas não se voltaram aos anseios de um ensino pensado para atender os 
propósitos da integração curricular e também às necessidades de formação intelectivas dos estudantes desse nível de ensino.

Entendemos que o perfil proposto para os professores que atuam nas Ciências Naturais é resultado de um "ciclo de políticas", que se manifesta de várias formas. Tais percepções foram acentuadas nas falas dos professores entrevistados, que se referiram aos termos "possíveis articulações", "visão integradora" e "questões profissionais"11 para relacionar o perfil do professor de Ciências Naturais aos vários condicionantes sociais. A contribuição desses professores foi essencial para ajudar a pensar a realidade que vem permeando o ensino dessa disciplina, em face das iniciativas de formação de professores conforme os propósitos defendidos.

Quando da organização das Diretrizes Curriculares Nacionais para os cursos da área de ciências, foi dado um encaminhamento diferenciado para as Ciências Naturais. Registramos aqui nossa percepção dos motivos que levaram à ausência da diretriz para a formação de professores de Ciências Naturais. A política de currículo tende a representar processos de negociação complexos que envolvem vários interesses. Inferimos que a falta dessa diretriz curricular nacional para a formação de professores de Ciências Naturais se justifica por interesses adversos a essa disciplina, o que tem contribuído negativamente para a oferta dessa Licenciatura e para a criação de um ambiente conflituoso que tem contribuído para a indefinição do perfil profissional adequado para atuar nessa área de conhecimento.

Por isso, enfatizamos que, especificamente no caso dos professores de Ciências Naturais, é necessária a sistematização de uma diretriz curricular nacional, pois sua inexistência tem contribuído para a confusão a respeito da formação docente e do perfil de profissional adequado para as Ciências Naturais. Compreendemos que a formação de docentes com um perfil que responda aos anseios dessa disciplina é a oferecida na licenciatura específica dessa área de conhecimento. Evidenciamos, por meio da análise das propostas curriculares selecionadas para este estudo, que as Licenciaturas em Ciências Naturais tiveram o intuito e o cuidado de definir questões teórico-metodológicas que apontam para a formação de um perfil profissional em consonância com as características da integração curricular, própria das Ciências Naturais.

Enfim, o "ciclo de políticas" nos possibilita perceber, por meio da historicidade dessa área de conhecimento, da legislação que foi dando respaldo ao ensino das Ciências, das produções teóricas sobre o tema, assim como das falas dos professores entrevistados, os vários condicionantes sociais. Nesse sentido, compreendemos que o conhecimento vai sendo socializado num emaranhado de relações, de vivências pautadas em interesses sociais e pessoais. Vai se efetivando o que Ball (2001a) chama de "eficácia da escola". Esse movimento simbólico é materializado na participação dos diversos "empreendedores de políticas", cuja influência vale também para essa área de conhecimento. Essa percepção nos instiga a maiores debates sobre o perfil do professor de Ciências naturais e a sistematização de uma Diretriz Curricular que oriente a oferta para a licenciatura voltada a essa área de conhecimento.

11 Essas expressões correspondem à ordem dos professores entrevistados: PB, PQ e PF. 


\section{Referências}

Aires, J. A. (2011, janeiro/abril). Integração curricular e interdisciplinaridade: sinônimos? Educação e Realidade. Porto Alegre, 36 (1), 215-230.

Ayres, A. C. M., Lima-Tavares, D. L., Ferreira, M. S., \& Selles, S. E. (2008). Disciplina escolar ciências e formação de professores: aproximações sócio-históricas nas licenciaturas de curta duração. In: Encontro nacional de didática e prática de ensino, 14, Anais... (p.1-20). Porto Alegre, RS.

Ball, S. J. (2001a). Cidadania global, consumo e política educacional. In: L. H. da Silva, (Org.), A escola cidadã no contexto da globalização. Petrópolis, RJ: Vozes.

Ball, S. J. (2001b, julho/dezembro). Diretrizes políticas globais e relações políticas locais em educação. Currículo sem Fronteiras, 1(2), 99-116.

Bianchetti, L., \& Jantsch, A. P. (2002, julho). Interdisciplinaridade e práxis pedagógica: tópicos para discussão sobre possibilidades, limites, tendências e alguns elementos históricos conceituais. Ensino e Re-vista, 10 (1), 7-25.

Carvalho, M. A. B. (2001). A concepção de ciências representada na prática pedagógica do professor licenciado para ensinar ciências. (Dissertação de mestrado), Maringá, PR.

Chassot, A. I. (1990). A Educação no Ensino de Química. Ijuí, RS: Unijuí.

Chassot, A. I. (1998). Inserindo a história da ciência no fazer educação com a ciência. In: A. I. Chassot \& J. R. Oliveira. Ciência, ética e cultura na educação. São Leopoldo, RS: Unissinos.

Fazenda, I. C. A. (2002). Integração e interdisciplinaridade no ensino brasileiro: efetividade ou ideologia? São Paulo, SP: Loyola.

Fracalanza, H., Amaral, I. A., \& Gouveia, M. S. F. (1986). O ensino de ciências no primeiro grau. São Paulo, SP: Atual.

Freire, P., \& Shor, I. (1986). Medo e ousadia: o cotidiano do professor. Trad. Adriana Lopez. Revisão Técnica de Lólio Lourenço de Oliveira, Rio de Janeiro, RJ: Paz e Terra.

Gozzi, M. E. (2016). A formação de professores para as ciências naturais dos anos finais do ensino fundamental. (Tese de doutorado). Programa de Pós-graduação em Educação para a Ciência e a Matemática, Maringá, PR.

Imbernon, R. A. L., Guimarães, E. M., Galvão, R. de M. S., Lima, A. C. de, Santiago, L. F., \& Jannuzzi, C. M. L. (2011). Um panorama dos cursos de licenciatura em ciências naturais (LCN) no Brasil a partir do $2^{\circ}$ seminário brasileiro de integração de cursos de LCN/2010. Experiências em Ensino de Ciências, 6 (1).

Japiassu, H. (1976). Interdisciplinaridade e patologia do saber. Rio de Janeiro, RJ: Imago. 
Lopes, A. C. (2004). Políticas de currículo: mediação por grupos disciplinares de ensino de ciências e matemática. In: A. C. Lopes, \& E. Macedo (Orgs.), Currículo de ciências em debate. Campinas, SP: Papirus.

Lei no 9.394 (1996). Lei de Diretrizes e bases da educação nacional. Lei no 9.394, de 20 de dezembro de 1996.

Lopes, A. C. (2008). Políticas de integração curricular. Rio de janeiro, RJ: EdUERJ.

Magalhães Júnior, C. A. de O, \& Pietrocola, M. (2010, julho). Análise de propostas para a formação de professores de ciências do ensino fundamental. Alexadria Revista de Educação em Ciência e Tecnologia, 3 (2), 31-58.

Parecer CNE/CES N. 67/2003. (2003) Referencial para as diretrizes curriculares nacionais, 2003. Recuperado de http://portal.mec.gov.br/cne/arquivos/pdf/CES0067. pdf.

Parecer CNE/CP 2 de 2015. (2015). Diretrizes Curriculares Nacionais para a Formação Inicial e Continuada dos Profissionais do Magistério da Educação Básica. Ministério da Educação. Aprovado em: 9/6/2015. Recuperado de http://portal.mec.gov.br/index. php?option $=$ com_docman\&view $=$ download $\&$ alias $=17625$ - parecer - cne-cp-2-2015aprovado-9-junho-2015\&category_slug=junho-2015-pdf\&Itemid=30192.

Parecer CEE/CES No 190/10, Processo No 1157/10: Renovação do Reconhecimento do Curso de Graduação em Ciências - Licenciatura - Campus de Goioerê, PR.

Popkewitz, T. S. (1992). Cultura, pedagogia e poder. Teoria e Educação, 5.

Popkewitz, T. S. (1997). Reforma educacional: uma política sociológica - poder e conhecimento em educação. Porto Alegre, RS: Artes Médica.

Santomé, J. T. (1998). Globalização e interdisciplinaridade: o currículo integrado. Porto Alegre, RS: Editora Artes Médicas Sul Ltda.

Resolução CNE/CP 1, de 18 de Fevereiro de 2002 (2002). Ministério da Educação. Recuperado de http://portal.mec.gov.br/seesp/arquivos/pdf/res1_2.pdf.

Resolução CNE/CEB 4 de 13 de julho de 2010. (2010) Ministério da Educação. Recuperado de http://www.seduc.ro.gov.br/portal/legislacao/RESCNE004_2010.pdf.

Resolução n. 2, DE 1. De julho de 2015. (2015). Ministério da Educação. Recuperado de http://www.abmes.org.br/legislacoes/visualizar/id/1750.

Secretaria de Educação Fundamental. (1998) Parâmetros curriculares nacionais: Ciências Naturais. Brasília: MEC / SEF. 138 p.

UEM, Projeto Pedagógico - Curso: Licenciatura plena em Ciências. (2009). UEM, CCE. DCI, Goioerê, PR. Recuperado de http://www.crg.uem.br/cms/index.php?option=com content\&view=article\&id=74\&Itemid=76. 
UEM, Projeto Pedagógico - Curso Ciências Biológicas. (2010). UEM, CCB, Maringá, PR. Recuperado de http://old.dbi.uem.br/curso_biologia/res04410.pdf.

UNIRIO, Projeto Pedagógico - Curso de Licenciatura em Ciências da Natureza. (2009). Centro de Ciências Biológicas e da Saúde - Instituto de Biociências, Rio de Janeiro, RJ. Recuperado de http://www2.unirio.br/unirio/ccbs/ibio/PPCNatureza.pdf.

UNIRIO, Projeto Pedagógico - Curso Noturno de Licenciatura em Biologia. (2010). Centro de Ciências Biológicas e da Saúde - Instituto de Biociências, Rio de Janeiro, RJ. Recuperado de http://www2.unirio.br/unirio/ccbs/ibio/ProjetoPedaggicoBiologiaNOVO.pdf

USP, Projeto Político Pedagógico - Curso de Licenciatura em Ciências da Natureza. (2013). Escola de Artes, Ciências e Humanidades, São Paulo, SP.

USP, Projeto Pedagógico (Reformulado) - Curso de Ciências Biológicas. (2015). Faculdade de Filosofia, Ciências e Letras de Ribeirão Preto, SP. Departamento de Biologia, 71-89. Recuperado de file://C:/Users/Administrador/Downloads/PROJETO\%20 PEDAGOGICO\%20CIENCIAS\%20BIOLOGICAS\%202015\%20(1).pdf.

Veiga-Neto, A. (2010, novembro). Tensões disciplinares e ensino médio. In: I Seminário nacional: Currículo em movimento - Perspectivas atuais, Anais... Belo Horizonte, MG.

Wortmann, M. L. C. (2003). Currículo e ciências - as especificidades pedagógicas do ensino de ciências. In: M. V. Costa (Org.). O currículo nos limiares do contemporâneo. 3. ed. Rio de Janeiro, RJ: DP\&A.

Maria Estela Gozzi

${ }^{\oplus}$ http://orcid.org/0000-0002-3684-6740

Universidade Estadual de Maringá

Departamento de Ciências

Maringá, Brasil

estelauem@yahoo.com.br

Maria Aparecida Rodrigues

${ }^{\oplus}$ http://orcid.org/0000-0001-6652-8009

Universidade Estadual de Maringá

Programa de Pós-Graduação em Educação para a Ciência e a Matemática

Maringá, Brasil

aparecidar@gmail.com

Submetido em 07 de Abril 2016

Aceito em 02 de Março 2017

Publicado em 31 de Agosto de 2017 